\title{
CHANGES IN CARDIAC STATUS DUE TO ISOLATED SYSTOLIC HYPERTENSION BY NON- INVASIVE STUDIES
}

Sourangsu Chatterjee ${ }^{1}$,Achinta Narayan Roy², Biswadev Basu Majumdar³, Soumitra Ghosh4, Bapilal Bala $^{5}$, Kaustav Bhowmick ${ }^{6}$, Avijit Moulick ${ }^{7}$

\section{HOW TO CITE THIS ARTICLE:}

Sourangsu Chatterjee, Achinta Narayan Roy, Biswadev Basu Majumdar, Soumitra Ghosh, Bapilal Bala, Kaustav Bhowmick, Avijit Moulick. "Changes in Cardiac Status due to Isolated Systolic Hypertension by Non - Invasive Studies".Journal of Evolution of Medical and Dental Sciences 2014; Vol. 3, Issue 02, January 13; Page: 347-355, DOI:10.14260/jemds/2014/1832

ABSTRACT: AIM: It was thought previously that morbidity and mortality are directly related to both Systolic and Diastolic blood pressure. However evidences from different studies suggest that systolic hypertension deserves more importance especially due to its profound effect on cardiovascular disease progression. Isolated systolic hypertension (ISH) has now increased amongst the elderly population due to increased longevity. METHOD: Total 240 patients of 65 - 89 years age group were taken as study group at the out-patient and in-door department of CNMC Kolkata and NBMC, Siliguri. All patients were divided into three groups based on systolic blood pressure: Gr A=SBP-140-159 $\mathrm{mmHg}$, Gr B=SBP-160-179 mmHg \& Gr C=SBP>180 mmHg with each group having age and sex matched 100 healthy normotensive control subjects. History, Clinical examination, ECG and Echocardiographic studies were done in the selected patients. Sophisticated tests were not done due to nonavailability. RESULTS: Major Electrocardiogram changes are left atrial enlargement, left ventricular hypertrophy with systolic strain, Inferior wall ischemia, both bundle branch blocks, bifascicular block, left axis deviation. Other minor changes were: antero- septal ischemia, septal wall ischemia, lateral wallischemia, right axis deviation, arrhythmia, and low voltage were also noted. Echocardiography in 2-D and M-ModeandEcho-Doppler assessment showed increased Intraventricular septal thickness (IVST), Left ventricular posterior wall Thickness (LVPWT) and Left ventricular mass index were the major changes. Left ventricular functional abnormality like diastolic dysfunction was another significant abnormality. CONCLUSION: Different anatomical \& functional changes in ISH are more prevalent in higher SBP group, and strong risk factor for future catastrophic cardiac events. It is an independent risk factor for CVS morbidity and mortality. Early therapeutic intervention along with life style modification therefore can prevent long term CVS complications.

INTRODUCTION: Isolated systolic hypertension (ISH) is a common form of hypertension in elderly person of both sex and it affects $2 / 3^{\text {rd }}$ of all individuals of hypertension between the ages of 65-89 years ${ }^{1}$. During the recent decades the importance of perceiving ISH has changed from a relatively benign condition to major cardiovascular risk factor and more recent data from Framingham study reinforces the prognostic significance of raised SBP and wide pulse pressure as independent risk factor $^{2}$. According to JNC 7 th report in person older than 50years, systolic BP $>140$ is much more important CVS risk factor than diastolic BP.

ISH is also a common antecedent of heart failure, kidney damage, blindness and other conditions. Heart failure may be due to LVH with resulting diastolic dysfunction with or without concomitant systolic dysfunction or myocardial infarction ${ }^{4}$. Though it was thought previously that morbidity and mortality from hypertension are directly related to both SBP and DBP, it is now 
evident that systolic hypertension deserves more concern and that is why interest in ISH in the elderly has increased in the last few years.

MATERIAL \& METHODS:240 cases of ISH with age and sex matched 100 cases healthy control subjects were selected for this study. All patients went thorough:

1) History takings, clinical examination including B.P. measurement(standard method) and any bruit in abdomen.

2) Chest X-ray PA and lateral view.

3) Bedside routine blood tests, relevant investigations like, Urea, Creatine, LFT, Lipid profile, electrolytes are done in every case.

4) Urinalysis

5) USG abdomen to see Kidney size, corticomedullary differentiation.

6) 12 lead ECG both restingand exercise

7) Echocardiography, 2D, M-mode and Doppler study.

\begin{tabular}{|c|c|}
\hline Inclusion Criteria & Exclusion Criteria \\
\hline $\begin{array}{c}\text { SBP }>140 \mathrm{mmHg} \text { and } \\
\text { DBP }<90 \mathrm{mmHg} .\end{array}$ & Obvious Secondary causes. \\
\hline Age: $65-89$ years. & $\begin{array}{c}\text { Subjects who were not receiving } \\
\text { antihypertensive therapy }\end{array}$ \\
\hline
\end{tabular}

Data Collection and Categorization were done according to the statistical software application. In this present study various 'Parametric test' like T test and 'Non parametric test' like Chi Square test, was done accordingly using the statistical software IBM-SPSS ver.16.Chicago. All the statistical significance tests were done assuming Level of Significance (P Value) less than 0.05 or 95\% confidence intervals.

RESULTS AND ANALYSIS: Distribution of B.P. in the subjects studied showed a wide range of S.B.P. (140 -230 mmHg.) with a mean $176.72 \mathrm{mmHg}$, whereas DBP was in the range of 70-88 $\mathrm{mmHg}$. (Mean $77.24 \mathrm{mmHg}$.) Mean SBP and DBP in control group being $124.6 \mathrm{mmHg}$. and $82.4 \mathrm{mmHg}$. respectively.

Mean age of the study subjects were 73.04 years and 70.76 years in men and women respectively with a mean body surface area were (BSA) 1.66and 1.45 in men and women respectively. Mean age of the controls were 74.01 years and 71.26 years in men and women respectively. Most common symptoms among the study group showed blurring of vision in $12 \%$, $26 \%$ of Group B \& C patients due to cataract, dyspnea on exertion in 14\%, 28\%, 36 exertion in \% of patients Group A, Group B \& Group C; dizziness in 4\%, 20\%, 28\% of cases; palpitation 15\%, 26\%, $\& 36 \%$ of the same. Easy fatigability, headache, anginal syncope and feature of CCF were also noted in a few percentages of cases.

Chest X-ray showed Cardiomegaly (CTR $>0.5$ ) in 12\%, 25\%, 34\% of Group A, Group B \& Group $\mathrm{C}$ patients and $6 \%$ in control group. Associated finding included increased pulmonary vasculature in $6 \%, 10 \%$ of Group B \& Group C patients Left atrial enlargement $4 \% 10 \%$ of Group B \& 
Group C patients; unfolding of aorta $20 \%$, calcification of aortic knuckle (8\%) and aortic aneurysm $2 \%$ of Group Ccases.

\begin{tabular}{|c|c|c|c|c|c|c|}
\hline \multirow{2}{*}{$\begin{array}{l}\text { Sl. } \\
\text { No. }\end{array}$} & \multirow{2}{*}{\multicolumn{2}{|c|}{ Finding }} & \multicolumn{3}{|c|}{ \%. of Patient } & \multirow{2}{*}{$\begin{array}{c}\text { Control } \\
(\%)\end{array}$} \\
\hline & & & Gr. A & Gr. B & Gr. C & \\
\hline 1 & L A enlargement & & 6 & 12 & 22 & \\
\hline 2 & L V hypertrophy & & 20 & 32 & 42 & 10 \\
\hline \multirow{5}{*}{3} & \multirow{5}{*}{$\begin{array}{l}\mathrm{S} T \text { changes, } \mathrm{T} \text { wave inversion } \\
\text { andQ wave } \\
\text { (suggestive of ischemia) }\end{array}$} & Inferior wall & 5 & 16 & 20 & 6 \\
\hline & & Infero- lateral wall & & & 4 & - \\
\hline & & Antero - septal & & & 6 & - \\
\hline & & Septal & & & 6 & - \\
\hline & & Lateral wall & & 6 & 10 & 4 \\
\hline 4 & T wave inversion & Systolic strain pattern & 4 & 26 & 40 & 8 \\
\hline \multirow{4}{*}{5} & \multirow{4}{*}{ Bundle Branch Block } & Left & 12 & 32 & 46 & - \\
\hline & & Right & 2 & 6 & & - \\
\hline & & A. V. block & 1 & 2 & & - \\
\hline & & Bifascicular Block & 2 & 4 & & - \\
\hline \multirow[t]{2}{*}{6} & Axis deviation & Left & 12 & 32 & 46 & 10 \\
\hline & & Right & 2 & 4 & 6 & - \\
\hline 7 & Abnormal Q wave & & - & - & & - \\
\hline 8 & Arrhythmia & & 6 & 2 & 10 & 4 \\
\hline 9 & R. V. H. & & & 2 & 6 & - \\
\hline 10 & Low voltage & & & & 3 & - \\
\hline
\end{tabular}

ECG showed Left atrial enlargement (LAE), Left ventricular hypertrophy (LVH), lateral wall ischemia, anteroseptal wall ischemia, infero-lateral wall and septal wall ischemia. Other notable abnormalities were systolic strain, LBBB, RBBB, LAD, RAD, Arrhythmia, low voltage, strain patternand nonspecific ST segment depression. [Fig. 1].

\begin{tabular}{|l|c|c|c|c|}
\hline \multirow{2}{*}{ Findings } & \multicolumn{3}{c|}{$\begin{array}{c}\text { \% } \\
\text { Subject }\end{array}$} & \multirow{2}{*}{ \%Control } \\
\cline { 2 - 4 } & Group A & Group B & Group C & \\
\hline L.A. diameter > 4cm & 8 & 18 & 32 & 8 \\
\hline $\begin{array}{l}\text { I.V.S.T. (d) } \\
>1.1 \mathrm{~cm}\end{array}$ & 24 & 46 & 68 & 4 \\
\hline $\begin{array}{l}\text { L.V.PWT (d) } \\
>1.1 \mathrm{~cm}\end{array}$ & 20 & 42 & 66 & 5 \\
\hline I.V.S.T: L.V. PWT = 1.3 & 16 & 20 & 42 & 4 \\
\hline L.V.M Index (gm./ m2) & & & & 8 \\
\hline Male > 135 gm./m2 & 30 & 56 & 70 & 8 \\
\hline Female > 111 gm./ m2 & 36 & 68 & 80 & 12 \\
\hline
\end{tabular}




\begin{tabular}{|l|c|c|c|c|}
\hline L.V. Functional Abnormality & & & & \\
\hline E. $<$ A & 42 & 64 & 78 & 16 \\
\hline E/A between 1-2 & & 8 & 12 & \\
\hline E >2 & & 2 & 4 & \\
\hline Pattern of Diastolic Dysfunction & & & & \\
\hline Delayed relaxation & 28 & 46 & 62 & 8 \\
\hline Pseudonormalization & & & 10 & 4 \\
\hline Restrictive filling & & & 4 & \\
\hline IVRT > 100 msec & 31 & 62 & & \\
\hline IVST + LVPWT > 2.5 cm & 18 & 36 & & \\
\hline \multicolumn{2}{|c|}{ Table - 2: Echocardiographic finding in ISH } \\
\end{tabular}

Routine Echocardiography was performed in all our patients. Left ventricular dimensions, both systolic and diastolic functional assessment were recorded in all patients. Anatomical abnormalities in IVS, LVPWT and Septal wall detected in this study.[Fig. -2 and 3]. Overall diastolic dysfunction was noted in a significant number of cases.

\begin{tabular}{|l|c|}
\hline \multicolumn{1}{|c|}{ Abnormal Parameters } & \% detected \\
\hline Increased IVST & 70 \\
\hline LVMI (gm. / m2) & 66 \\
\hline Diastolic dysfunction (E < A) & 64 \\
\hline Increased LVPWT & 62 \\
\hline Increased IVRT & 62 \\
\hline \multicolumn{2}{|c|}{26} \\
\hline Table 3: Echo - detected L. V. abnormalities \\
in order of frequency \\
\hline
\end{tabular}

Echocardiographic analysis revealed various abnormalities in patients of ISH which were significantly greater than those of control. Functional abnormality especially diastolic dysfunctions were frequent in these subjects than in control group.[Fig. 3].

DISCUSSION: From different studies it is well established that ISH is more common in people older than 60 years and raised SBP and wide pulse pressure are independent cardiovascular risk factor. It alters LV mass, LV geometric pattern, systolic and diastolic functions. Dyspnea on exertiona prominent symptom of LV dysfunction, was noted in 14\%, 28\%, $36 \%$ exertion in of patients Group A, Group B \& Group C patients; with features of CHF in 6\% and $10 \%$ of Group B \& C patients, anginal pain in $8 \%, 10 \%, 30 \%$ of Group A, Group B \& Group C subjects respectively and majority showed ECG evidence of Inferior and inferolateral wall ischemia. A study from Chandigarh reported hypertension as a common coronary risk factor $(14.5 \%)^{5}$. A strong association of CAD with SBP was found in various previous study ${ }^{6,7}$. Considering clinical features LV enlargement was detected by chest X-ray (CTR> 0.5) in 12\%, 25\%, 34\% of Group A, Group B \& Group C patients while echocardiography detected LVH was 36\%, 68\%, 80\% of Group A, Group B \& Group C female patients; and 30\%, 58\%, $70 \%$ of the same group male patients respectively. In one study by Savage at al ${ }^{8}$, LV enlargement 
was detected in $7 \%$ of hypertensive subjects in x-ray chest PA view while echocardiography detected LVH in $67 \%$ cases. Comparing our study with this study Echo-LVH was nearly same but variability in radiologic finding can in part be explained by differences in sample size, age distribution, systolic BP level, associated IHD etc. Increased pulmonary vascularity in chest x-ray $6 \%$ \& 10\% in Group B \& Group C patients respectively possibly due to presence of heart failure cases in this study dysfunction.

Significant ECG abnormality showed LAE in in $6 \%, 12 \%, \& 22 \%$ of patients Group A, Group B \& Group C cases(based on Tarazi R.C. et al criteria ${ }^{9}$. LA enlargement may be the reflection of diastolic dysfunction. Frequency of electrocardiographic LVH in 20\%, 32\%, and 42\% of Group A, Group B \& Group C case(various criteria used in this study were Sokolow Lyon, cornel voltage and Estes scoring criteria) whereas echocardiographically determined LVH echocardiography detected LVHwas36\%, $68 \%, 80 \%$ of Group A, Group B \& Group C female patients;and 30\%, 58\%, 70\% of the same group male patients respectively, a result that was consistent with previous study of Surawicz-B ${ }^{10}$ and Pearson A.C. et all 11. Abnormalities concerning ischemia of different wall of the myocardium and strain pattern were consistent with Framingham Heart study and SHEP trail, where in people with age group of 65-94 years with SBP> $180 \mathrm{mmHg}$. had 3-4 fold increased in the risk of CAD compared with those SBP $<12012,13$. (Table-1).

Anatomical and functional cardiac changes in control group were much lower. The abnormal findings in control group were probably due to age related increased incidence of CAD, LVH and not due to ISHbut in presence of ISH those values are increased about 3-4 fold which is consistent with Framingham study 12. Echocardiographic findings in hypertensive subjects show changes with increasing age and Body surface area (BSA) similar in direction and degree to that seen in normotensive subjects ${ }^{8}$ The magnitude of this changes suggest that the effect of both age and BSA should be accounted for in any attempt to assess the effect of hypertension on Echocardiographic measurements ${ }^{8}$, this is accomplished in this study. Echocardiographic parameters were used to assess both anatomic and functional abnormalities of heart.

One significant anatomic abnormality was Mean LA enlargement of $3.37 \mathrm{~cm}$ (range $2.7-4.7$ $\mathrm{cm}$ ) showing slightly higher mean value than that of control group $3.08 \mathrm{~cm}$. However LAE $>4 \mathrm{~cm}$ was detected in 8\%, 18\%, 32\%of Group A Group B \& Group C cases and 8\% in control group. Savage et at ${ }^{9}$ found LAE in $5 \%$ of hypertensive subjects but in their study hypertensive subjects were younger than our study and this effect of ISH in relation to duration was shorter in this study.

\section{* Major Anatomic abnormalities studied were -}

a. IVST diameter $>1.1 \mathrm{~cm}$ in 24\%, 46\%, 68\%\%of Group A Group B \& Group Cstudy cases but only $4 \%$ cases of control group. $(\mathrm{P}<0.05$, $\mathrm{z}$ value $=8.62$. $)$

b. LVPWT - changes in LVPWT $>1.1 \mathrm{~cm}$ were noted in $20 \%, 42 \%, 66 \%$ of Group A Group B \& Group case and only in $4 \%$ of control group. $(\mathrm{Z}$ value $=8 . .621$ and $\mathrm{P}<0.05)$

c. LVH or LVMI (gm. $/ \mathrm{m}^{2}$ ) - Most important changes noted were LVH and LVMI (LVH defined ${ }^{14}$ by LVMI $>135 \mathrm{gm} / \mathrm{m}^{2}$ in male and $>111.9 \mathrm{gm} . / \mathrm{m}^{2}$ in female) was detected in was $36 \%, 68 \%, 80 \%$ of Group A, Group B \& Group C female patients; and 30\%, 58\%, 70\%ofthe same group male patients respectively. Whereas in control group it was $8 \%$ and $12 \%$ respectively.

[In male: $\mathrm{SD}(\mathrm{E})=9.615$, mean difference $=20.33$, Zvariate $>2, \mathrm{P}<0.05$.In female: SD $(\mathrm{E})=7.1$, mean difference $=32.7$ standard variate $(\mathrm{Z})=4.6, \mathrm{P}<0.05$.] 
This result of this study had given similar results like that of other studies e.g. Laver M.S, et al in Framingham Heart study 1991, (Hypertension is an establishment determinant and precursor of LVH and LVM), ${ }^{15}$ Misseri FH, 1996 (Association of SBP with LVH and LVM), Kar A.K. el., Savage et al (structural abnormality of heart in $61 \%$ of hypertensive patient).

Based on gender specific criteria echo-LVH was found to be more frequent in female patientsthan males \& in control group also a higher frequency of LVH was noted. The reason for the discrepancies of LVH between men and women is not clear. However it may be due to selective reduction in physical activity among men with hypertension, a substantial prevalence of clinically apparent heart disease associated with mild LVH among apparently normal males or a greater propensity of women to develop marked concentric LVH in response to hypertension for as yet undefined reason 16,17 .

In this study we have also got septal hypertrophy (IVST: PWT)> 1.3)in Group B(6\%) \& Group C (14\%) cases with increased LV mass which is consistent with previous study report. (Savage et al8mean IVST, LVPWT, LVMI for ISH patient were significantly higher than the control group.

\section{- Major Functional Assessment -}

1. Systolic function - Ejection fraction (EF) and Fractional shortening (FS) of study subjects were nearly same of that control group. Mean EF was $65.83 \%$ and mean FS was 35.42. Only two subjects with reduced EF (<50\%) showed systolic dysfunction. Though mean FS (35.42\%) was nearly close to that of control, a significant number showed reduced FS $(<34 \%)$.

2. Diastolic function - as assessed by decreased E- velocity and enhanced A-velocity with $\mathrm{E} / \mathrm{A}<1$ was noted in 42\%, 64\% 78\% Group A, Group B \& Group C (P < 0.05$)$ but only in $16 \%$ of control showed similar diastolic dysfunction. Almost all patients except a few (who showed diastolic dysfunction) had increased LV mass determined by echocardiography. Thus LVH with LV filling abnormality are very common in subjects with ISH, results being consistent with Person A -C et al11.

3. Another important parameter IVRT increased in $8 \% 42 \% 60 \%$ of Group B \& Group CCASES against $18 \%$ of control subjects which was statistically significant $(Z$ Variate $=2.72, \mathrm{P}<0.05)$. Different patternof diastolic dysfunctions assessed were:

a) Delayed relaxation pattern - ( $<<$ A, IVRT $>100 \mathrm{msec}$ andtdec $220 \mathrm{mcec}$.) found in 28\%, 46\%, $52 \%$ of\% Group A, Group B \& Group C cases but only $8 \%$ in control group (SE (d) $=4.49$ mean difference $=12.24, \mathrm{Z}=2.72, \mathrm{P}<0.05)$.

b) Pseudo normalization pattern - $(\mathrm{E} / \mathrm{A}=1-2 \mathrm{tdec}=150-200$ mece; IVRT $=60-100 \mathrm{msce})$ in $10 \%$ of Group C cases.

c) Restrictive filling pattern - (E / A $>2$, tdec $<150$ msce, IVRT $<60$ msce.) seen in 4\% of Group cases. $4 \%$ of control group showedpseudo normalization pattern but none showed restrictive pattern. Restrictive filling pattern indicates more severe diastolic dysfunction and pulmonary congestion. An Edec time (tdec) < $150 \mathrm{msec}$. indicates a stiff ventricle and poor prognosis. [Table no. -3].

CONCLUSION: Isolated systolic Hypertension is a common association with elderly people and an independent risk factor for cardiovascular disease and its prognosis. A good relationship was noted between anatomical \& functional abnormality along with the level of systolic pressure and it may 
contribute to the decreased exercise capacity and subendocardial ischemia specially during exercise due to lower coronary reserve and increase $\mathrm{O}_{2}$ demand. Increased $\mathrm{LV}$ mass with $\mathrm{LV}$ filling abnormality is a common consequence of ISH which occurs more often in women than in men and is considered to be an important risk factor for sudden death, , myocardial ischemia, ventricular arrhythmia and heart failure. Thus it constitutes an high risk sign rather than a benign adaptive process, emphasizing the importance of early recognition and timely initiation of antihypertensive therapy to prevent complications. In a country like ours where all the facilities are not available, proper selection of patients of ISH and utilizing minimum available gazettes can go a long way in initiating appropriate in time therapy for delaying, retarding, and preventing cardiovascular morbidity and mortality in course of the disease progression due to the long term effect of ISH causing various cardiac complications.

\section{REFERENCES}

1. Wilking SVBetal. Determinants of Isolated systolic hypertension. JAMA 1988;260: 3451 - 3455.

2. Franklin SS, Khan SA, Wong ND, Larson MG, Levy LD. Is pulse pressure is more importantthan SBP in predicting coronary heart diseases events? Circulation 1999; 100: 354 -360.

3. Levy D, Larson MG, Vasan RS, Kannel WB and HO KHL. The progression from hypertension to congestive heart failure. JAMA 1996;275: 1557 - 1562.

4. Korotkoff NS, on the subjects of measuring blood pressure, Bull Imp. Mil Med Acad. St. Peterberg 1905; II: 365 -367, (Translation) Geddes LA, Hoff HE and Badger AS;Introductionof the auscultatory methodof measuring bloodpressure. Cardiovascular Res. Cent. Bull (Houston) 1967; 5: 57 - 74 .

5. Bikkina M, Levy $\mathrm{D}$, etal. Left ventricular and risk ofstroke in en elderly cohort. The Framinghamheart study. JAMA 1994; 272: 33 - 36.

6. Wander GS, KhuranaSB, Gulati R et al. Epidemiology of Coronary heart disease in rural Punjab population. Prevalence and correlation with various riskfactor. Ind. Heart Journal 1994; 146 (b):319 - 323 .

7. Morris JNet al.Incidence and prediction of ischemia heart disease in London Busmen. Lancet 1966; 2: 553.

8. Rosenman R Het al. A study of comprehensive blood pressure measures in predicting riskof coronary heart disease. Circulation1976; 54:51.

9. SavageDDet al. Echocardiographic assessment of cardiac anatomy and function in hypertensive subjects. Circulation, 1979;59: 623.

10. TaraziRCet al. Electrocardiographic changes reflecting left atrial abnormality in hypertension. Circulation1966; 34: 818.

11. SurawiczB. Electrocardiographic diagnosis of chamber enlargement. J. Am. Coll. Cardiol1986;8: 711.

12. PeasonACet al. Prevalence of left ventricular hypertrophy and diastolic filling abnormalities in elderly patients with ISH J. Am. Coll. Cardiol. 1987; 9: 244A.

13. Kannel WB. Blood pressure as a cardiovascular risk factor:Prevention and treatmentJAMA1996; 275: 1571 - 1576.

14. Applegate WB, Pressel S, Wittes J, Luhr J, Shekelle RB, Camel GHet al.Implication of systolic hypertension in the elderly program. SHEP Co- operative Research Group. 193; 21: 335 -343. 


\section{ORIGINAL ARTICLE}

15. LauerMS, Anderson KM and Levy D. Influence of contemporary versus30 year blood pressure level on left ventricular mass and geometry: The Framingham Heart Study. J. AM. Col. Cardiol. 1987; 18: 1287 -1294.

16. Hammond IWDevereux RB, Alderman MH, Lutas EM, Spitzer MC et al. The Prevalence and correlates of Echocardiographic left ventricularhypertrophy among employed patients with uncomplicated hypertension. J. Am. Coll. Cardiol.1986;7: 639.

17. Topol EJ, Traill T.A, Fortuin N.J et al. Hypertension hypertrophic cardiomyopathy of the elderlyN. Eng. J. Med. 1985; 312:277 - 283.

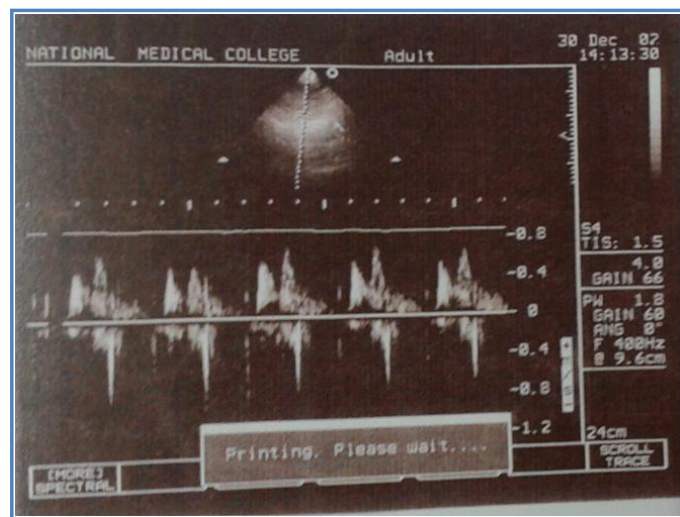

FIG. 1: ECHO DOPPLTR STUDY SHOWING ALTER E \& A RATIO

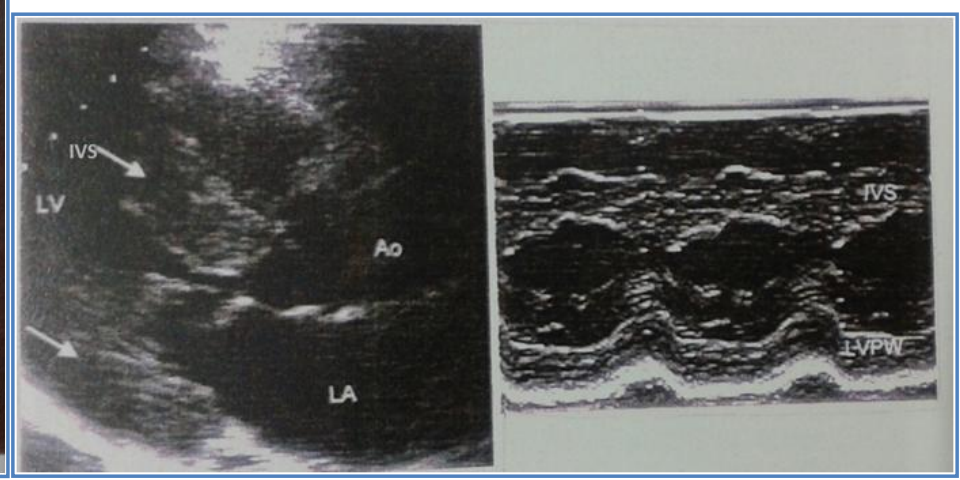

FIG-2. 2D \& M-Mode echo-showing increased IVST and LVPWT

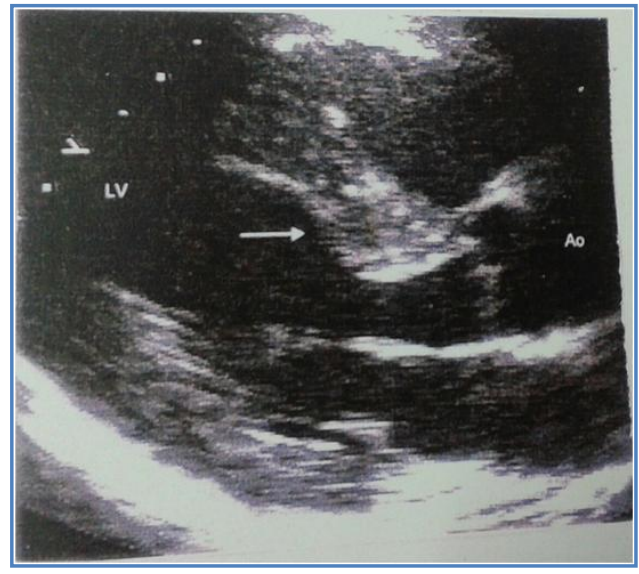

FIG-3. 2D \& M-Mode echo-showing increased IVST 


\section{AUTHORS:}

1. Sourangsu Chatterjee

2. Achinta Narayan Roy

3. Biswadev Basu Majumdar

4. Soumitra Ghosh

5. Bapilal Bala

6. Kaustav Bhowmick

7. Avijit Moulick

\section{PARTICULARS OF CONTRIBUTORS:}

1. Associate Professor, Department of Neurology, North Bengal Medical College and Hospital.

2. Associate Professor, Department of Medicine, North Bengal Medical College and Hospital.

3. Resident, Department of Medicine, Neotia Hospitals.

4. Professor, Department of Medicine, IPGMER, Kolkata.

5. Assistant Professor, Department of Medicine, North Bengal Medical College and Hospital.
6. Post Graduate Trainee, Department of Medicine, North Bengal Medical College and Hospital.

7. Assistant Professor, Department of Medicine, Calcutta National Medical College, Kolkata.

\section{NAME ADDRESS EMAIL ID OF THE CORRESPONDING AUTHOR:}

Dr. Biswadev Basu Majumdar, C/o. Bijan Basu Majumdar, Dangapara, P.O. Debnagar, Dist. Jalpaiguri, Pin - 735101, West Bengal.

Email - dr.biswadev.basu@gmail.com

Date of Submission: 17/12/2013.

Date of Peer Review: 18/12/2013.

Date of Acceptance: 31/12/2013.

Date of Publishing: 09/01/2014. 